\title{
Quotas in Brazilian Public Universities: Good or Bad Idea?*
}

\author{
Eduardo C. Andrade**
}

Summary: 1. Introduction; 2. Model; 3. Competitive Equilibrium; 4. Effects of Quotas; 5. Conclusion.

Keywords: affirmative action; quotas; efficiency; public and private universities.

JEL codes: H0; H41; I22; I28.

In Brazil, there have been some initiatives to introduce a system of affirmative action quotas in public universities, to benefit either black students or individuals who have studied in public schools. In this paper, I develop a simple model to analyze theoretically the effects of the introduction of such a system on the efficiency of expenditures in higher education. The effects on the overall efficiency of the total investments (public and private) can be beneficial, nonexistent, or detrimental, depending on the degree of the liquidity constraint of the low-income families and the quality of the public university vis-à-vis private ones.

Existem algumas iniciativas no sentido de introduzir um sistema de quotas nas universidades brasileiras para estudantes negros ou que tenham estudado em escolas públicas. Neste trabalho, um modelo teórico é desenvolvido para analisar os impactos da introdução deste sistema de quotas na eficiência dos gastos em educação universitária. O resultado encontrado é que estes impactos podem ser positivos, inexistentes ou negativos, dependendo em grande medida da qualidade da universidade pública vis-à-vis à universidade privada e o grau de restrição de liquidez das famílias de baixa renda.

\footnotetext{
${ }^{*}$ This paper was received in Feb. 2003 and approved in Feb. 2004. I am grateful to Danniel Cardoso Oliva and Heitor Hiroaki Hirota for their research assistance. I would like to thank two anonymous referees and the participants in the Latin American Econometric Society Meeting in Panama and SBE in Porto Seguro, both in 2003, where an earlier draft of this paper was presented. Of course, I am the sole responsible for any remaining errors and shortcomings of the paper.

${ }^{* *}$ Ibmec São Paulo. E-mail: eduardo.andrade@ibmec.br
} 


\section{Introduction}

The Brazilian educational system is characterized by a great disparity in terms of the qualities of its schools and universities. On the one hand, in the primary and secondary levels, the best schools are in general the privates ones. Families who can afford do send their children to private schools, even though they have the option of public education free of charge. The difference between the two types of school's quality is significant. The offspring's expected greater future income related to the better school compensates the families' foregone consumption today in paying the school tuition. In general, only low-income families opt to send their children to public schools: either because they can not afford the private option or because their utility cost of sending their children to the private school is greater than the corresponding cost for high-income families.

On the other hand, however, the best universities are in general the public ones. ${ }^{1}$ All candidates take the admissions test, and those who achieve the greatest scores obtain the right to attend the public universities. It is no surprise, then, that those individuals who attended private primary and secondary schools are better prepared and perform better in these exams. In general, the private universities of higher quality are not superior enough to justify families, whose children have the right to attend public universities, in paying the private university tuition. Hence, most of the students who attend public universities come from high-income families.

In order to counterbalance the advantage of the individuals from the highincome families in the admission tests, there have been some initiatives to introduce some form of affirmative action into the Brazilian public universities' entrance system. The intended beneficiaries of these policies are either black individuals, or individuals who have studied in public schools. They are the target because they in general come from low-income families. ${ }^{2}$ The state of Rio de Janeiro has already introduced a system of quotas, under which $50 \%$ of all students of the state public universities must have attended public schools and $40 \%$ of them must

\footnotetext{
${ }^{1}$ All undergraduate students have to take a national exam (called 'Provão') in order to obtain their university degree. Based on this exam, the government provides ranks of the universities in different courses. In 2002, the number of public universities among the top 20 universities in different fields is the following: Business (13), Economics (13), Law (17), Medicine (17), Pedagogy (16), and Physics (16).

${ }^{2}$ One could argue that the government should subsidize education, partially or fully, only for those individuals coming from low-income families, and eliminate the system of free tuition for all individuals, independently of their family background, who pass the admission test for the public universities. However, there are no movements in this direction.
} 
be black students. The state of Bahia also has a system under which $40 \%$ of all students of the state university students must be black students. Other states are in the process of adopting a similar scheme. On the federal level, there are plans to establish quotas directed to black students in the federal universities. These plans would guarantee the admission of a certain number of individuals from the target groups in public universities, in particular those who obtained the highest scores, relative to the target group, in the admission exams. Hence, individuals not from the target groups who have performed better in these tests can lose their right to attend public universities.

The objective of this paper is to analyze theoretically the effects of the introduction of the system of quotas into the Brazilian public universities' entrance system, assuming that the government maintains free tuition for all individuals who pass the public university admissions test. ${ }^{3}$ This type of policy represents an income transfer to its beneficiaries, as they can attend better universities in general without incurring the tuition cost. However, this impact is not the focus of the analysis. ${ }^{4}$ This paper concentrates on the effects of quotas on the efficiency of the expenditures in education.

Efficiency is measured in three different ways. First, it can be measured by the quality of the labor force produced by the public investments in education. Second, it can be measured by the quality of the labor force produced by the overall (sum of public and private) investments in education. Finally, it can be measured by whether the educational system guarantees that individuals with the greatest academic abilities ${ }^{5}$ are reaching the university, regardless of their income's family background. The main contribution of this paper is to indicate under which circumstances the introduction of quotas can be beneficial or detrimental to the efficiency of the investments in education at the higher level.

In this paper I develop a two-period model in order to mimic the family's problem of deciding whether or not to send a child to university. A parent who opts to send a child to university has two options: either the funded public university, if the child passes the admissions test, or the private university, with the cost of paying tuition. There is a probability that a child who is sent to university becomes an individual with a high level of human capital, which depends positively on his or her ability. The introduction of quotas alters the allocation of human resources between the two types of universities in the ways described above.

\footnotetext{
${ }^{3}$ The system of quotas loses its importance if the government finances higher education, partially or fully, for only those individuals who can not afford it.

${ }^{4}$ For an extensive discussion on this topic, see Holzer and Neumark (2000).

${ }^{5}$ In this paper, when the term ability is used alone, it always means academic ability.
} 
This paper's model suggests the following results. With quotas, individuals with lower ability on average attend public universities, as the average grades on the admission tests are lower. ${ }^{6}$ This reduces the efficiency of public investments in higher education. When the quality of both types of universities (private and public) is the same, the effect on the total efficiency of the system depends in great part on the degree of the liquidity constraint of the beneficiaries of the system of quotas. In the case that this constraint is not very tight, the beneficiaries would have been able to afford a private university anyway. Quotas simply move individuals with greater and lower ability, respectively, to private and public universities, without any impact on overall efficiency. In the case of a tight constraint, individuals previously deprived of the possibility of attending any university go to a public university. Quotas reduce the link between income's family background and the capacity of an individual to attend a university. The consequence is a reduction in the skill premium and a weaker economic incentive for the least able individuals to continue attending private universities. The overall ability of the university students and the efficiency of the system increases.

When the quality of private universities is greater, quotas move individuals with greater abilities to them, making more efficient the allocation of human resources between both types of universities. This does not occur without quotas, when individuals opt to attend public universities because they are free, even though they are of lower quality than the private universities. Quotas correct this distortion and increase the overall efficiency of the system. Finally, when the quality of public universities is greater, the shift in the allocation of human resources between both types of universities caused by the introduction of quotas is not the most efficient one. Individuals with the greatest abilities are taken away from the universities with greater quality, which implies a less efficient system.

This paper is related to the literature that analyzes theoretically the efficiency effects of affirmative action in education, which stresses four different issues. ${ }^{7}$ First, it discusses if the university admission process would be more or less efficient in the absence of affirmative action policies. In particular, Garrat and Marshall (1994) shows that, under certain conditions, university admissions procedures based on

\footnotetext{
${ }^{6}$ The first admissions test with quotas at the University of the State of Rio de Janeiro (UERJ) took place in 2003. There was an important difference between the grades of the student with the lowest score from the non-target group and from the target group who was accepted in the university in its different programs, with the former obtaining higher grades. Here are some examples (with all grades out of 100): dentistry school (77.5 for the non-target group versus 6.25 for the target group), history department (71.25 versus 63.25), and medical school (92.5 versus $64)$.

${ }^{7}$ See Holzer and Neumark (2000) for a review of this literature.
} 
addmiting students above certain cutoffs of grade and test scores may be efficient. However, this type of admission procedure may not be efficient if grades and test scores are imperfect measures of student quality or returns from education across students are not positively correlated with previous grade and test scores. As a result, it would open up the possibility that the introduction of quotas can be efficient. Second, there is a point made by educators that diversity enhances the quality of education, as students learn from each other's experience and perspective, which would work in favor of the introduction of quotas. Nevertheless, there is no empirical evidence supporting this idea. Third, imperfections in the market for university admissions can generate an inefficient equilibrium. In particular, imperfect capital markets to finance education prevent minorities, which are more likely to come from low income families, to attend an university. This inefficiency could be reduced by the introduction of quotas. Finally, minority students who benefit from preferential treatment may have worse academic achievements and performance in comparison with other students from nonminority groups. For hypothesis related to this view, see D'Souza (1991) and Murray (1994).

The novelty of this paper is to adapt a theoretical framework developed by Caucutt and Kumar (2003) to analyze the impact on efficiency of the introduction of quotas in Brazilian public universities. In contrast to this paper, Caucutt and Kumar (2003) analyzes the effects of increasing higher education subsidies in the US, from their already substantial levels, on inequality, welfare, and efficiency. As they do not analyze the impact of quotas, they do not have to make any distinction between the two types of universities, private and public, as I do here. In comparison with the literature, this paper assumes that grades and test scores are perfect measures of student quality and returns from education across students are positively correlated with previous grade and test scores. Furthermore, it is analyzed two cases: either when low income families are credit constrained or not.

The rest of this paper is organized as follows. The next section presents the structure of the model. Section 3 discusses the competitive equilibrium without quotas. In section 4, the effects of quotas on efficiency are analyzed, and the paper ends with a last, concluding section.

\section{Model}

The model employs a two-period economy. There are two types of families, which differ by the parent's level of human capital. At time $t=0$, parent has either a high or a low level of human capital. Each parent works, receives wages, decides whether to send his child to university, consumes, and dies. At time $t=1$, the 
child becomes a worker with high or low level of human capital, depending on the educational decision of his parent, receives a wage, and consumes. The measure of each generation (and the number of workers in each period) is constant and is normalized to one. Let $n_{h, t}$ and $n_{l, t}$ be the fraction of individuals, respectively, with high and low levels of human capital at time $t$. Note that $n_{h, 0}=n_{h, 0}^{*}$ and $n_{l, 0}=n_{l, 0}^{*}$ are exogenously given, and $n_{h, 0}^{*}+n_{l, 0}^{*}=1$.

As I do not model the schooling decision, it is assumed that all children have a school degree and are able to attend university. However, they differ in their ability to perform well at university and become an individual with a high level of human capital. A child with ability $a$ who attends a private university becomes an individual with high or low level of human capital, respectively, with probability $\pi_{p r}(a)$ and $\left(1-\pi_{p r}(a)\right)$. In the case of attending a public university, the equivalent probability can differ and is denoted by $\pi_{p u}(a)$. If the quality of the public university is greater than the private, then $\pi_{p u}(a)>\pi_{p r}(a), \forall a$. The inequality reverses if the opposite holds, that is, if the private university has a higher quality. This feature of the model limits the heterogeneity to two levels of human capital, and therefore to two income levels, which simplifies the analysis. ${ }^{8}$ If a child does not attend university, he has the lower level of human capital with probability equal to one. Let $F($.$) be the distribution function for ability on the support [0,1], and$ $f($.) be the corresponding density function. As in Caucutt and Kumar (2003), the distribution is identical across types and within families of the same type, and all ability draws are independent of each other. ${ }^{9}$

\footnotetext{
${ }^{8}$ See Andrade (1998) for an example of the use of this framework.

${ }^{9}$ The ability of an individual to attend university and acquire a high level of human capital is determined in great part by two factors. The first is the individual's innate or cognitive ability, and is independent of the social environment where the individual grows up. There is no reason to assume that the distribution of this innate ability differ between groups of individuals who differ by family income status (see Heckman (1995)). The second factor is related to expenditures in education received by the individual before entering university. This second factor is greatly affected by the income of the individual's family. For example, high-income families are capable of paying for extra courses and better quality schools. See discussion in Becker (1993). Combining these two factors, one could imagine that the distribution function for a child's ability differ across types of families, but is identical within the same type of family. Nonetheless, the results in this paper would not undergo any change assuming this difference in distribution across types of families, as will be discussed in section 4 . Hence, I assume the same distribution for simplicity.
} 
Assumption 1: $a \in[0,1], 0 \leq \pi_{j}(a) \leq 1, \pi_{j}^{\prime}(a)>0, \pi_{j}^{\prime \prime}(a)<0, \forall a$, and $\pi_{j}(0)=0$, $j=p r, p u$.

There are important additional differences between the private and public universities, besides the possible differences in quality mentioned above. The public university is free of charge, and the number of students who can attend it is exogenously determined and equal to $v$. As the number of applicants to fill these places is greater than $v$, it is necessary to have some form of rationing. The students with the right to attend the public university are selected using a ranking of the individuals' abilities, which is assumed to be public information; they are the $v$ individuals with greater ability who choose to attend the public university. The cost of each student is equal to $E$ units of consumption, which the government finances. ${ }^{10}$ As will be pointed out below, the government imposes an income tax at time $t=0$ to finance these expenditures in education. The private university cost is also equal to $E$ units of consumption, and every family who is willing to pay this fee can send a child to a private university.

The parent whose child has ability $a$ and is one of the selected students to attend the public university has three options: sending the child to attend the public or the private university, or alternatively, letting the child remain solely with a school degree. The family's problem can be written in the following way:

$$
\begin{aligned}
& \max _{p u, p r, s}\left\{u\left((1-\tau) w_{i, 0}\right)+\beta\left[\pi_{p u}(a) u\left(w_{h, 1}\right)+\left(1-\pi_{p u}(a)\right) u\left(w_{l, 1}\right)\right]\right. \\
& u\left((1-\tau) w_{i, 0}-E\right)+\beta\left[\pi_{p r}(a) u\left(w_{h, 1}\right)+\left(1-\pi_{p r}(a)\right) u\left(w_{l, 1}\right)\right] \\
& \left.u\left((1-\tau) w_{i, 0}\right)+\beta u\left(w_{l, 1}\right)\right\}, i=h, l
\end{aligned}
$$

where:

$\tau$ is the income tax;

$w_{i, t}$ is the wage of individual with $i$ level of human capital at time $t$, and the utility function has the usual properties. The first term within the parenthesis in the family's problem indicates the public university option. At $t=0$, the family consumes its wage net of taxes and sends its child to a free public university. At $t=1$, the child who becomes a worker either with high or low level of human capital earns his or her wage. The second term indicates the private university

\footnotetext{
${ }^{10}$ This feature of the model tries to mimic the current system of students' selection to the Brazilian public universities. All applicants must take the same exam (called "vestibular") prepared by the universities. The accepted students are those who achieve the highest scores. In the model, it is assumed that the students who achieve the highest scores are the ones with greater abilities.
} 
option. The difference with respect to the first option is that the family pays both taxes and the cost of the private education $(E)$ at $t=0$, and the probability of the child becoming a worker is now based on the quality of the private university. The last term is the option of not sending the child to university at all. The family pays taxes and the child becomes a worker with low level of human capital. ${ }^{11}$ The other families, whose children are not among those selected to attend the public university, have a similar problem, with the difference that they do not have the first option of sending their children to public university. ${ }^{12}$

Four comments are worth noting before proceeding to describe production in this economy. First, there is no capital market to finance education. This assumption is commonly used and widely accepted. ${ }^{13}$ Second, the only type of bequest allowed in this model is through investments in education. Other types of bequests are not empirically relevant for most families, even in the most developed countries. ${ }^{14}$ Third, to simplify the analysis, the education sector is not explicitly modelled in this paper. Hence, the expenditures on education (the cost $E$ ), either public or private, are not collected as revenues by any individual in the economy. In fact, sending a child to college involves a real cost of $E$ units of consumption, which can be financed privately or publicly. One can imagine that there is a backyard technology in which each family spends $E$ units of consumption (privately or publicly financed) and transform his child into an individual with high level of human capital with a probability $\pi$. Finally, the price (cost) of private education is assumed to be fixed and equal to $E$. With this assumption, the number of students that the private universities absorb is not fixed and it is endogenously determined. In other words, price is constant and the number of students in the private universities can vary. Implicitly it is assumed a set-up in which there is perfect competition in the private market for education with competitors having the same cost structure. As a result, the long run market supply of education in the private section is perfectly elastic. ${ }^{15}$

\footnotetext{
${ }^{11}$ It should be clear that this last option is never chosen by the parent whose child is selected as one of the students to attend public university for free.

${ }^{12}$ To simplify the analysis, the tuition $E$ is the only cost of higher education. This paper ignores the opportunity cost of foregone earnings, an important component of the cost of education, and assume that the child who do not attend university can not work at time $t=0$. The reason is that it does not affect the qualitative results in this paper, as argued in footnotes 21 and 28 .

${ }^{13}$ See Becker (1991) for an extensive discussion of this topic.

${ }^{14}$ See Stokey (1998) for an extensive discussion of this topic.

${ }^{15}$ In the short run, one can think that there is idle capacity in the tertiary private education sector, which is not far from reality. Hence, the price would still be constant in the short run. One of the referees suggested that a more realistic approach would be to consider that the supply curve of education in the private sector is perfectly inelastic. With this assumption, price would
} 
There is a single non-storable good in the economy produced by firms operating in a competitive market. The inputs in the production process are the two types of labor, individuals with high and low levels of human capital. Therefore, there is no physical capital in this economy. The production function presents constant returns to scale and is as follows:

$$
Y_{t}=A\left[\theta\left(N_{h, t}+\gamma N_{l, t}\right)^{d}+(1-\theta)\left(N_{l, t}+\varepsilon N_{h, t}\right)^{d}\right]^{\frac{1}{d}}
$$

where:

$A>0$;

$0<\theta, \varepsilon, d, \gamma<1$

$\gamma \ll \varepsilon ;$

$N_{h, t}$ and $N_{l, t}$ are, respectively, the number of individuals with high and low levels of human capital employed in the production process at time $t$. Note that the possible values for the variables $N_{l, t}$ and $N_{h, t}$ are in the interval [0,1], as the number of workers in each period is constant and is normalized to one. Hence, total output can be expressed as a function of the fraction of individuals with a high level of human capital in each period.

Both types of individuals provide two distinct productive services, which one may think of as mental effort ("brains") and physical effort ("brawn"). ${ }^{16}$ The first and second terms within the square brackets can be thought of, respectively, as "brain" and "brawn", with the parameter $\theta$ indicating the importance of the mental effort. Thus, mental and physical efforts are combined into an aggregate by a CES technology with an elasticity of substitution, $\frac{1}{1-d}$, that exceeds unity. ${ }^{17}$ The parameter $\varepsilon$ is the relative efficiency of the individuals with high level of human capital in supplying physical effort. Whereas the parameter $\gamma$ is the relative efficiency of the individuals with low level of human capital in providing the mental effort. Both parameters $(\varepsilon$ and $\gamma)$ are important in determining the wage differential between the individuals with high and low level of human capital, as assumption 2 below indicates.

There are two important ideas behind this production function. First, as $\gamma$ is assumed to be close to zero, the individuals with high level of human capital are the main providers of "brain". Second, as $\varepsilon<1$, the individuals with a high level of human capital can perform (almost) all the tasks that the other type of labor

be endogenous and the number of individuals who could attend private universities would be fixed. In footnote 29, I will speculate on how the results in this paper would change under this alternative approach.

${ }^{16}$ This type of production function is used in Stokey (1996) and Caucutt and Kumar (2003).

${ }^{17}$ If $d$ were equal to one, mental and physical effort would be perfect substitutes. 
can, and more. The following assumption simplifies the analysis and guarantees that the wages paid to the individuals with a high level of human capital are always greater than the ones for the individuals with a low level of human capital, for all possible values for $N_{h, t}$ and $N_{l, t}$.

Assumption 2: $\varepsilon>\left(\frac{1-\theta}{(1-\gamma) \theta}\right)^{\frac{1}{1-d}} \cdot 18$

The results in this paper do not depend on this assumption, which is made just for convenience and to simplify the analysis. In any equilibrium with private investment in education, since it is costly (cost of $E$ ), families finance their children's education only if they anticipate a positive skill premium (a positive difference between the wage paid to the individuals with high and low levels of human capital). If this skill premium is negative, there is no private investment in education. As a result, the wage premium would increase, inducing private university enrollment. ${ }^{19}$

The government's budget constraint has to be in equilibrium. The number of students in the public university is fixed and equal to $v$, with the cost of $E$ units of consumption per student. The only source of revenues are the income tax imposed at $t=0$. Therefore:

$$
\tau\left(N_{h, 0} w_{h, 0}+N_{l, 0} w_{l, 0}\right)=v E
$$

\section{Competitive Equilibrium}

This section discusses the equilibrium of the model. It is of interest to analyze the equilibrium with two characteristics that are true of the current Brazilian educational system. The first characteristic is the existence of private expenditures in education from both types of families, those having both low and high level of human capital. It could be the case that the expected skill premium resulting only from the public expenditures in education would not be large enough to create economic incentives for individuals to invest their own resources in private education. Let $w_{i, 1}^{\prime}(i=h, l)$ be the wage if the $v$ individuals with greatest ability attend public university and if there is no investment in private education and $a_{p u}$ be the ability level of the individual with the lowest ability who has the right to attend the public university. The following assumption eliminates the possibility

\footnotetext{
${ }^{18}$ This assumption indicates that $\varepsilon$ (the coefficient of the individual with a high level of human capital in the production of "brawn") is large enough to guarantee that $w_{h, t}>w_{l, t}$.

${ }^{19}$ See assumption 4 below for a necessary condition of the existence of positive expenditures in private education, which is the type of equilibrium of interest in this analysis.
} 
of existing only public investment in education:

Assumption 3: $\beta \pi_{p r}\left(a_{p u}\right)\left[u\left(w_{h, 1}^{\prime}\right)-u\left(w_{l, 1}^{\prime}\right)\right]>u\left((1-\tau) w_{i, 0}\right)-u\left((1-\tau) w_{i, 0}\right.$ $-E)$.

The above assumption indicates that there are some parents from both types of families whose children do not have the right to attend public universities, and who are made better off by investing in private education instead of not sending their children to university. This condition holds even if the individuals with the greatest abilities attend public universities, which would lead to the lowest possible wage premium with only public expenditures in education.

The second characteristic that is true of the current Brazilian educational system is the fact that individuals in general opt to attend public universities, because they are free, even if a private university has a higher quality. That is, even if $\pi_{p r}(a)>\pi_{p u}(a), \forall a$. In order to restrict the analysis to an equilibrium with this characteristic, the following assumption is made: ${ }^{20}$

Assumption 4: For any $a, a \in\left[a_{p u}, 1\right], u\left((1-\tau) w_{i, 0}\right)-u\left((1-\tau) w_{i, 0}-E\right)>$ $\beta\left(\pi_{p r}(a)-\pi_{p u}(a)\right)\left(u\left(w_{h, 1}^{\prime}\right)-u\left(w_{l, 1}^{\prime}\right)\right)$.

The above assumption indicates that the differences in quality between both types of university $\left(\pi_{p r}(a)-\pi_{p u}(a)\right)$ are not large enough to justify the investment $E$ in private education.

Before proceeding to define the competitive equilibrium in this economy, it is worth characterizing the behavior of both types of parents with respect to the decision to send their child to private university.

Proposition 1: For any given wage differential: there exists an unique $a_{p r, i}^{*}$ which is a function of the wage differential $\left(w_{h, 1}-w_{l, 1}\right)$ such that $a_{p r, i}^{*}\left(w_{h, 1}-w_{l, 1}\right) \in$ $\left(0, a_{p u}\right), i=h, l$, and a parent with $i$ level of human capital sends his child to university if $a \geq a_{p r, i}^{*}\left(w_{h, 1}-w_{l, 1}\right)$, and does not otherwise; and $a_{p r, h}^{*}\left(w_{h, 1}-w_{l, 1}\right)<$ $a_{p r, l}^{*}\left(w_{h, 1}-w_{l, 1}\right) \cdot{ }^{21}$

The first part of the above proposition indicates that there is threshold ability behavior for both types of families. Parents with high and low levels of human capital send their children to private university only if their children's ability is greater than, respectively, the threshold values $a_{p r, h}^{*}$ and $a_{p r, l}^{*}$. If a child has an

\footnotetext{
${ }^{20}$ With this assumption, the family whose child has the right to attend the public university always chooses to send its child to public university. The other two options become redundant.

${ }^{21}$ See in the appendix the proof of all propositions in this paper.
} 
ability lower than this threshold value, it is not profitable to pay for a private education and obtain a lower immediate utility. This is the case because the expected future gain in utility, as a result of the expenditure $E$ in education today, is very small, as the probability of this child becoming an individual with a high level of human capital is very low.

The second part of the above proposition shows that parents with a high level of human capital send children to university with lower ability vis-à-vis parents with a low level of human capital. Under assumption 2, the former receive greater wages and are richer than the latter. As a consequence, their utility cost of paying the cost of education and sending children to private university is lower, lowering the ability required to compensate for that cost.

I now turn to the definition and the proof of existence and uniqueness of the equilibrium:

Definition 1: Given $v, E$, and $n_{i, 0}^{*}$, a competitive equilibrium is characterized by $n_{i, 1}^{*}, w_{i, 0}^{*}, w_{i, 1}^{*}, a_{p u}^{*}$ and $a_{p r, i}^{*}\left(a_{p r, i}^{*} \in\left(0, a_{p u}\right)\right)$ such that $(i=h, l)$ : given wages, firms maximize profits; the labor market clears, that is, $N_{h, t}=n_{h, t}^{*}$ and $N_{l, t}=n_{l, t}^{*}(t=0,1) ; a_{p u}^{*}$ is obtained from the following equation for $v, v=$ $n_{h, 0}^{*} \int_{a_{p u}^{*}}^{1} f(a) d a+n_{l, 0}^{*} \int_{a_{p u}^{*}}^{1} f(a) d a=\int_{a_{p u}^{*}}^{1} f(a) d a$; given wages and $E, a_{p u}^{*}$ and $a_{p r, i}^{*}$ solve the university decision problem of family $i$ in (1); the government budget constraint is in equilibrium; and the law of motion for the variable $n_{h}$, which is given by:

$$
\begin{aligned}
n_{h, 1}^{*} & =n_{h, 0}^{*}\left[\int_{a_{p u}^{*}}^{1} \pi_{p u}(a) f(a) d a+\int_{a_{p r, h}^{*}}^{a_{p u}^{*}} \pi_{p r}(a) f(a) d a\right] \\
& +n_{l, 0}^{*}\left[\int_{a_{p u}^{*}}^{1} \pi_{p u}(a) f(a) d a+\int_{a_{p r, l}^{*}}^{a_{p u}^{*}} \pi_{p r}(a) f(a) d a\right] .
\end{aligned}
$$

Proposition 2: There exists a competitive equilibrium and it is unique. ${ }^{22}$

This unique equilibrium has the following characteristics. First, all families whose children have the right to attend a public university send their children to a public university. Second, there are children coming from both types of families

\footnotetext{
${ }^{22}$ If one takes into consideration the opportunity cost of foregone earnings as an additional cost of higher education, the equilibrium would still be characterized by threshold abilities. However, the ability threshold abilities would be greater for boty types of families as it would be an additional cost of attending university.
} 
who attend private universities. Finally, the skill premium and the fraction of individuals with a high level of human capital at $t=1$ are positive.

Implicit in the analysis up to this point is the assumption that $(1-\tau) w_{l, 0}>E$. This assumption means that the net wages of parents with a low level of human capital are greater than the cost of private education, which implies that these individuals have enough resources to finance their children's private education. As there is no capital market to finance education, this assumption is a necessary one to have an equilibrium in which some children whose parents have a low level of human capital attend private universities. It is easy to show that there is also a unique competitive equilibrium in the special case when $(1-\tau) w_{l, 0}<E$. In the next section, the effects of quotas are also analyzed for this special case.

\section{Effects of Quotas}

This section analyzes the effects of quotas in public universities according to three variables: the efficiency of public expenditures in education; the efficiency of the total, private and public, expenditures in education; and the modulus of the difference in the threshold abilities behavior of both types of families.

Before discussing how the system of quotas can be introduced into the model, it is important to define formally the efficiency of expenditures in education. Following Caucutt and Kumar (2003), I use the ratio of the number (measure) of students who turned out to be individuals with a high level of human capital to the public or total resources expended in educating them. Hence, without quotas, the efficiency of the public $\left(E F F_{p u}^{*}\right)$ and total $\left(E F F_{t o}^{*}\right)$ expenditures in education are, respectively, equal to:

$$
\operatorname{EFF}_{p u}^{*}=\frac{n_{h, 0}^{*}\left[\int_{a_{p u}^{*}}^{1} \pi_{p u}(a) f(a) d a\right]+n_{l, 0}^{*}\left[\int_{a_{p u}^{*}}^{1} \pi_{p u}(a) f(a) d a\right]}{v E}
$$

and

$$
E F F_{t o}^{*}=\frac{n_{h, 1}^{*}}{\left(v+n_{h, 0}^{*} \int_{a_{p r, h}^{*}}^{a_{p u}^{*}} f(a) d a+n_{l, 0}^{*} \int_{a_{p r, l}^{*}}^{a_{p u}^{*}} f(a) d a\right) E}
$$

Note that the more efficient the total investments in education are, ceteris paribus, the greater is the total level of output at time $t=1$. This is the case because output in this model is a positive function of the fraction of individuals with a high level of human capital, and this fraction increases with the efficiency of the investments in education. Moreover, there is nothing to preclude the efficiency 
in the public sector from dropping at the same time that efficiency in the private sector increases, or vice-versa. Obviously, the efficiency of the whole educational sector is the more relevant variable.

One can consider that an efficient educational system is one in which individuals with the greatest abilities are capable of reaching the university, independently of their income's family background. Hence, the lower the modulus of the difference in the threshold abilities behavior of both types of families, which is equal to $D I F^{*}=\left|a_{p r, h}^{*}-a_{p r, l}^{*}\right|$ in the equilibrium without quotas, the more efficient is the educational system. Without quotas, proposition 1 indicates that parents with a high level of human capital (and greater income) send children to university with lower ability vis-à-vis parents with a low level of human capital (and lower income). It is interesting to analyze whether the introduction of quotas into the system affects this feature of the competitive equilibrium.

Without the system of quotas and under assumption 4, the $v$ parents whose children possess the greatest ability opt to send their children to public universities. The ability range of the individuals who attend public universities is equal to $\left[a_{p u}^{*}, 1\right]$, independently if their parents have high or low level of human capital. The introduction of quotas into the system has the effect of changing the individuals who have the right to attend public universities and, thus, the ability range of the individual who attend public universities.. This change occurs formally in the following way. The $q$ individuals with the lowest ability levels compared to other individuals of their background, who might have had the right to attend the public university and whose parents have a high level of human capital, lose their right to attend public universities. In their place, the $q$ individuals with the highest ability levels among individuals of their backgrounds, who would not have had the right to attend a public university and whose parents have a low level of human capital, acquire that right.

Therefore, the new ability range of the individuals who attend public universities are the following. It becomes equal to $\left[a_{p u, h}^{* *}, 1\right]$ and $\left[a_{p u, l}^{* *}, 1\right]$, respectively, for those individuals whose parents have high and low level of human capital. Note that $a_{p u, h}^{* *}>a_{p u}^{*}>a_{p u, l}^{* *}$. The abilities $a_{p u, h}^{* *}$ and $a_{p u, l}^{* *}$ are obtained, respectively, from the following equations: $q=n_{h, 0}^{*} \int_{a_{p u}^{*}}^{a_{p u, h}^{* *}} f(a) d a=n_{l, 0}^{*} \int_{a_{p u, l}^{* *}}^{a_{p u}^{*}} f(a) d a .^{23}$

The way the system of quotas is modeled in this paper tries to mimic the types of quotas that have been or are in the process of being implemented in the Brazilian educational system. These quotas are intended to benefit black students and individuals who have attended public schools, who come in general

\footnotetext{
${ }^{23}$ It is assumed that the number of quotas in the public university is such that $a_{p u, l}^{* *}>a_{p r, l}^{*}$.
} 
from lower-income families. This is the reason for directing the quotas in the model to families whose parents have a low level of human capital. Moreover, the choice of the beneficiaries of the quotas is based on the admissions test. Those students whose low-income background qualifies them for quota admissions, who achieve the highest scores in this exam compared to other students of their backgrounds, and who would not gain the right to study in the public universities without quotas, are the ones who acquire the right to attend the public university. They replace students who achieve the lowest scores on the exam compared to other students not eligible to benefit from the quotas, and who would have the right to attend the public university without a quota system. The change in the ability range of the individuals who attend public university with the introduction of the system of quotas mentioned above seeks to mimic this choice of the beneficiaries of the quotas. Recall that in this model it is assumed that there is a direct link between ability and performance on the admissions test.

Let $E F F_{p u}^{* *}, E F F_{t o}^{* *}$ and $D I F^{* *}$ be, respectively, the efficiency of the public expenditures in education, the efficiency of the total expenditures in education and the modulus of the difference in the threshold abilities behavior of both types of families, when the system of quotas are introduced. Formally, we have:

$$
\begin{gathered}
E F F_{p u}^{* *}=\frac{n_{h, 0}^{*}\left[\int_{a_{p u, h}^{* *}}^{1} \pi_{p u}(a) f(a) d a\right]+n_{l, 0}^{*}\left[\int_{a_{p u, l}^{* *}}^{1} \pi_{p u}(a) f(a) d a\right]}{v E} \\
E F F_{t o}^{* *}=\frac{n_{h, 1}^{* *}}{\left(v+n_{h, 0}^{*} \int_{a_{p r, h}^{* *}}^{a_{u, h}^{* *}} f(a) d a+n_{l, 0}^{*} \int_{a_{p r, l}^{* *}}^{a_{p u}^{* *}} f(a) d a\right) E} \\
D I F^{* *}=\left|a_{p r, h}^{* *}-a_{p r, l}^{* *}\right|
\end{gathered}
$$

where:

$a_{p r, i}^{* *}$ is the threshold value for family $i$ with quotas, that is, if a child has an ability lower than this threshold, it is not profitable to pay for private education; and $n_{h, 1}^{* *}$ is the fraction of individuals with high level of human capital at $t=1$ with quotas.

The main objective of this paper is to compare $E F F_{p u}^{*}$ with $E F F_{p u}^{* *}, E F F_{t o}^{*}$ with $E F F_{t o}^{* *}$, and $D I F^{*}$ with $D I F^{* *}$, which is exactly the goal of the remainder of this section. In other words, it analyses the effects of the introduction of the system of quotas on the measures of efficiency defined above. I divide the analysis into two parts. First, it is assumed that the quality of both types of universities, 
private and public, is the same. Formally, this means that $\pi_{p r}(a)=\pi_{p u}(a), \forall a$. Second, it is considered that either the quality of the public university is greater $\left(\pi_{p r}(a)<\pi_{p u}(a), \forall a\right)$ or the inverse holds $\left(\pi_{p r}(a)>\pi_{p u}(a), \forall a\right)$.

Before proceeding in the analysis, it is worth making some comments on the characteristic of the competitive equilibrium if the ability of an individual to attend university and acquire a high level of human capital differ across type of families, as discussed in footnote 8. For example, one can assume that the ability range of the students coming from high and low income families are, respectively, $[a, b]$ and $[c, d]$, with $b>d,{ }^{24}$ to capture the idea that students from high income families are, on average, better prepared to attend university as their families are capable of paying for extra courses and better quality schools. With these new ranges, the competitive equilibrium would still be characterized by a positive fraction of students from both types of families attending public and private universities and not attending any type of university. ${ }^{25}$ Note that quotas would have an affect at the margin, with individuals from high (low) income families losing (gaining) their right to attend public universities. Therefore, the effects of quotas on the efficiency of the educational sector would not change if one drops the simplifying assumption that the ability range of the students coming from high and low income families is the same, as suggested in footnote 8.

\subsection{Same quality in private and public universities}

In this subsection, I consider the effects of the introduction of the system of quotas on the efficiency of the public and total expenditures in education, and the difference in the threshold ability behavior of both types of families. I analyze two possible cases in which the quality of both universities, public and private, are the same. In the first case, the condition $(1-\tau) w_{l, 0}>E$ holds, that is, the net wages of the individuals with a low level of human capital are greater than the cost of private education. In the second case, the sign of this inequality is reversed.

\footnotetext{
${ }^{24}$ One could make the additional assumption that $0<c<a<d<b$. Furthermore, it is reasonable to maintain the main features of assumption 1 , that is, $a \in[0, b], 0 \leq \pi_{j}(a) \leq 1$, $\pi_{j}^{\prime}(a)>0, \pi_{j}^{\prime \prime}(a)<0, \forall a$, and $\pi_{j}(0)=0, j=p r, p u$.

${ }^{25}$ Assuming that $(1-\tau) w_{l, 0}>E$, and there are individuals coming from low income families with a level of ability high enough that allows them to attend a public university.
} 
Proposition 3: With $(1-\tau) w_{l, 0}>E$ and $\pi_{p r}(a)=\pi_{p u}(a), \forall a$, the introduction of the system of quotas reduces $E F F_{p u}\left(E F F_{p u}^{* *}<E F F_{p u}^{*}\right)$ and does not affect $a_{p r, l}, a_{p r, h}, E F F_{t o}$ and DIF $\left(a_{p r, l}^{* *}=a_{p r, l}^{*}, a_{p r, h}^{* *}=a_{p r, h}^{*}, E F F_{t o}^{* *}=E F F_{t o}^{*}\right.$, and $\left.D I F^{* *}=D I F^{*}\right)$.

When $(1-\tau) w_{l, 0}>E$, the above proposition indicates that the introduction of the system of quotas does not affect either the efficiency of the total expenditures in education $\left(E F F_{t o}\right)$, or the difference in the threshold ability behavior of both types of parents $(D I F)$. However, it reduces the efficiency of the public expenditures in education $\left(E F F_{p u}\right)$.

The economic intuition behind these results runs as follows. With quotas, individuals with lower ability on average attend public universities. With the same amount of public expenditures in education $(v E)$, the fraction of individuals who acquire a high level of human capital is lower. This fact explains the reduction in $E F F_{p u}$.

Moreover, on the one hand, individuals who benefit from the quotas simply move from the private university to the public one. The quality of the universities is the same, so families opt for the one free of charge. On the other hand, individuals who lose their right to attend public universities move to private universities. This increases the average ability of those individuals attending private universities. Combining these two effects and with the assumption that the quality in both types of universities are the same, the variable $E F F_{\text {to }}$ does not undergo any change. That is, the loss in efficiency of the public investments is offset exactly by the gain in efficiency of the private ones.

As there is no change in the private incentives to invest in education, the expected skill premium is the same and $a_{p r, l}$ and $a_{p r, h}$ do not change, that is, $a_{p r, l}^{* *}=a_{p r, l}^{*}$ and $a_{p r, h}^{* *}=a_{p r, h}^{*}$. Hence, total investments in education and the fraction of individuals who acquire a high level of human capital are equal to those figures in the equilibrium without quotas. Finally, the system of quotas works as a way of transferring income from families who lose their right to send their children to the public university (the high-income families) to the ones who acquire the right (the low-income families). 
I now turn to the analysis of the situation in which parents with a low level of human capital do not have enough resources to pay for private education, that is, when $(1-\tau) w_{l, 0}<E .^{26}$

Proposition 4: With $(1-\tau) w_{l, 0}<E$ and $\pi_{p r}(a)=\pi_{p u}(a), \forall a$, the introduction of the system of quotas reduces $E F F_{p u}\left(E F F_{p u}^{* *}<E F F_{p u}^{*}\right)$ and $D I F\left(D I F^{* *}<\right.$ $\left.D I F^{*}\right)$, and increases $a_{p r, h}\left(a_{p r, h}^{* *}>a_{p r, h}^{*}\right)$, and $E F F_{t o}\left(E F F_{t o}^{* *}>E F F_{t o}^{*}\right)$.

The above proposition asserts that the introduction of the system of quotas is beneficial when $(1-\tau) w_{l, 0}<E$. In spite of the reduction in $E F F_{p u}$, the other indicators of efficiency of the educational sector, $D I F$ and $E F F_{t o}$, improve.

These results can be explained in the following way. As in the previous case, with quotas, individuals with lower ability on average attend public universities, leading to a reduction in $E F F_{p u}$. The difference now is that the beneficiaries of the quotas would not have been attending private universities under the system without quotas, as their families could not afford them. With this change, the number of individuals from low-income families who attend public universities increases and the ability threshold of those individuals is lower, moving from $a_{p u}^{*}$ to $a_{p u, l}^{* *}$. Ceteris paribus, the expected number of individuals with a high level of human capital at time $t=1$ increases and the expected skill premium drops. Hence, the economic incentive to invest in private education diminishes. The implications are that, at the margin, the number of individuals from the highincome class who attend private universities diminishes and the ability threshold of those individuals is greater. Combining the effects on the ability threshold of the individuals from both types of families who attend university, the result is a lower value for the variable $D I F$.

Finally, the total amount invested in education is lower in this new equilibrium with quotas. Public investments remain unaltered, but the amount of private investment is lower. Nonetheless, the fraction of individuals with a high level of human capital at time $t=1$ increases because individuals with a greater ability on average are attending university. This fact explains a greater $E F F_{t o}$. The lower efficiency of the public investments in education is more than offset by the greater efficiency of the private investments.

\footnotetext{
${ }^{26}$ In the special case when $(1-\tau) w_{l, 0}<E$, there is no private investment in education from families whose parents have a low level of human capital. In this case, the variable DIF is defined in the following way: $D I F=\left|a_{p r, h}^{*}-a_{p u, l}^{*}\right|$.
} 
The two above propositions show very different effects of the system of quotas in terms of the efficiency of the educational sector. The results are very dependent on whether individuals with a low level of human capital (the poorer individuals) can or cannot afford to pay for their children to attend a private university. In reality, one might think that many beneficiaries of the system of quotas would be those who could actually pay for a private education. In this case, the quotas would simply be a way of transferring income to poorer families. However, it is not unlikely that some beneficiaries would not be able to attend a university without the quotas, allowing the quotas to make the educational system more efficient. With the same quality in both types of universities, the likely result of the system of quotas would probably be a mix of those obtained in the two above propositions.

\subsection{Different quality in private and public universities}

The objective of this subsection is to analyze the effects of the system of quotas on the different variables that measure the efficiency of the educational sector when the quality of both types of universities, public and private, are different. Throughout this subsection, it is assumed for simplicity that $(1-\tau) w_{l, 0}>E$, that is, low income families have enough resources to finance private education. Assuming that the public university has a higher quality, the following result is obtained:

Proposition 5: With $\pi_{p u}(a)>\pi_{p r}(a), \forall a$, the introduction of the system of quotas reduces $E F F_{p u}, E F F_{t o}, a_{p r, l}, a_{p r, h}$ and $D I F\left(E F F_{p u}^{* *}<E F F_{p u}^{*}, E F F_{t o}^{* *}<\right.$ $E F F_{t o}^{*}, a_{p r, l}^{* *}<a_{p r, l}^{*}, a_{p r, h}^{* *}<a_{p r, h}^{*}$, and $\left.D I F^{* *}<D I F^{*}\right)$.

As in the previous subsection, with quotas, public expenditures in education become less efficient. As before, the reason is that the ability of individuals who attend the public university is on average lower.

The explanation for the reduction in $E F F_{t o}$ runs as follows. If the ability threshold for both types of individuals attending private universities $\left(a_{p r, l}^{*}\right.$ and $\left.a_{p r, h}^{*}\right)$ did not change with the introduction of quotas, the number of individuals with a high level of human capital at time $t=1$ would be lower and the skill premium greater. The reason is that some of the individuals with the greatest abilities would be taken away from the universities of higher quality, the public ones. The allocation of human resources between the two types of universities would thus not be the most efficient one. Hence, individuals would have a greater economic incentive to invest in education and the ability thresholds $\left(a_{p r, l}^{*}\right.$ and $\left.a_{p r, h}^{*}\right)$ could not stay the same. The new equilibrium is one with a lower ability threshold 
for both types of individuals. With more individuals with lower ability attending the university and the inefficient allocation of human resources between both types of universities, $E F F_{t o}$ is necessarily lower. Due to the concavity of the probability function, the reduction in $a_{p r, l}$ is greater than the one in $a_{p r, h}$, for a given increase in the skill premium. Hence, $D I F$ is lower in the new equilibrium. The ideal reduction in the variable $D I F$ should come concomitantly with the increase in the efficiency of total expenditures in education, which is not the case here. ${ }^{27}$

The following proposition presents the effect of quotas when the private university has a greater quality.

Proposition 6: With $\pi_{p u}(a)<\pi_{p r}(a), \forall a$, the introduction of the system of quotas reduces $E F F_{p u}\left(E F F_{p u}^{* *}<E F F_{p u}^{*}\right)$, and it increases $E F F_{t o}, a_{p r, l}, a_{p r, h}$ and $D I F\left(E F F_{t o}^{* *}>E F F_{t o}^{*}, a_{p r, l}^{* *}>a_{p r, l}^{*}, a_{p r, h}^{* *}>a_{p r, h}^{*}\right.$, and $\left.D I F^{* *}>D I F^{*}\right)$.

The explanation of the results in the above proposition is analogous to the one provided for proposition 5. For the same reason as before, the public investments in education are less efficient. With quotas, if the ability threshold for both types of individuals attending private universities $\left(a_{p r, l}^{*}\right.$ and $\left.a_{p r, h}^{*}\right)$ did not change, the number of individuals with a high level of human capital at time $t=1$ would be greater and the wage premium would be lower. The reason is that some of the individuals with the greatest abilities would be moved to the university of higher quality, the private one. They would had previously opted for the public university, because it is free of charge. ${ }^{28}$ The allocation of human resources between the two types of universities becomes more efficient. Hence, the individuals would have less economic incentive to invest in education and the ability thresholds $\left(a_{p r, l}^{*}\right.$ and $\left.a_{p r, h}^{*}\right)$ could not stay the same. The new equilibrium is one with a higher ability threshold for both types of individuals. With a greater ability of individuals who attend university on average and the more efficient allocation of human resources between both types of universities, $E F F_{\text {to }}$ is necessarily greater. Due to the concavity of the probability function, the increase in $a_{p r, l}$ is greater than the one in $a_{p r, h}$, for a given reduction in the skill premium. Hence, DIF is greater. This is the side effect of the imposition of quotas when the quality of the

\footnotetext{
${ }^{27}$ When $(1-\tau) w_{l, 0}<E$, the introduction of quotas increases the number of individuals from low-income families who attend university and the ability threshold of those individuals is lower. This effect tends to reduce the negative effect on $E F F_{t o}$ of the introduction of quotas when the public university has a higher quality.

${ }^{28}$ See assumption 4 above.
} 
private university is greater. ${ }^{29,30,31}$

\section{Conclusion}

There are some initiatives to introduce some form of affirmative action in the Brazilian public universities. The intended beneficiaries of these policies are either black individuals or individuals who have studied in public schools. The analysis in this paper suggests that, if one concern of policymakers is the efficiency of the educational system, the introduction of the system of quotas should be adopted with caution.

It could be the case that many beneficiaries of quotas would be families who could actually pay for a private education. Quotas would then simply be a way of transferring income to low-income families. However, it is not unlikely that some beneficiaries would not be able to attend a university without the help of quotas. The reduction in the link between income's family background and the capacity of an individual to attend a university leads to an overall efficiency of the system.

If adopted, quotas should not be implemented across public universities and

\footnotetext{
${ }^{29}$ The qualitative results in the propositions in this section would not suffer any change if one takes into consideration the opportunity cost of foregone earnings as another cost of higher education. For example, in propositions 4 and 6 , the introduction of quotas, ceteris paribus, reduces the skill premium. Hence, the incentive to attend university decreases, and more individuals with low level of human capital would give up school and start working at $t=0$. Then, it reduces the opportunity cost of attendig university. Therefore, if one takes into consideration the opportunity cost, the effects of quotas on the threshold abilities $\left(a_{p r, i}\right)$ is reduced, without affecting the qualitative results. Similar analysis can be done about the results in propositions 3 and 5 .

${ }^{30}$ The effect of quotas on the efficiency of public and total expenditures in education would not suffer any change if one considers that the price of private education is endogenous and the number of individuals who could attend private universities are fixed, as discussed in footnote 14. For example, in propositions 4 and 6, the introduction of quotas, ceteris paribus, reduces the skill premium and the incentive to attend university. With perfectly inelastic supply curve of private education, price of education would drop the necessary amount to maintain constant the number of individuals attending private university. As a result, the fraction of indivuals who turn out to have the high level of human capital at $t=1$ would not change, but with a much lower cost as tuition is lower. Therefore, efficiency of total expenditures in education increases. The explanation for the change on the efficiency of public expenditures in education is the same, even if the cost of private education is not fixed. As $a_{p r, i}$ does not change with flexible price of education, then DIF does not change. Similar analysis can be done about the results in propositions 3 and 5

${ }^{31}$ When $(1-\tau) w_{l, 0}<E$, the introduction of quotas increases the number of individuals from low-income families who attend university and the ability threshold of those individuals is lower. This effect tends to augment the positive effect on $E F F_{t o}$ of the introduction of quotas when the private university has a higher quality. At the same time, it reduces DIF.
} 
courses within the same university indiscriminately. With quotas, some individuals who have performed better on the admissions exams lose their right to attend public universities. If the relationship between the performance in these exams and academic ability is strong, inevitably the efficiency of the public expenditures in higher education is reduced. In other words, there is a decrease in the quality of the labor force produced by these public investments. However, the main concern of the policymakers should be the overall efficiency of the educational system.

In this regard, quotas could make the system more efficient when the quality of courses in private universities is greater. Without quotas, individuals may opt to attend public universities because they are free, when the difference in quality between both types of universities (public and private) is not great enough to justify incurring the cost of private tuitions. Quotas would correct this distortion and allocate human resources in a way that pushes individuals with greater abilities to attend the more qualified universities. The overall efficiency of the system increases. However, the opposite occurs when the quality of courses in public universities is higher. With quotas, there is a shift in the allocation of human resources between both types of universities, which turns out not to be very efficient. Individuals with the greatest abilities are taken away from the universities with greater quality, which implies a less efficient system.

The Ministry of Education carries out regular evaluation of the Brazilian universities in various ways. One of these forms is through a national exam, called "Provão", which all undergraduate students have to take in order to obtain a university degree. Based on this exam, the government ranks universities in different courses of study. One possibility is to use these ranks to structure the system of quotas in a way suggested by the analysis in this paper, in order to improve the overall efficiency of the system. That is, quotas should be less used (or even non-existent) for the most highly ranked public universities or courses.

The structure of the model in this paper does not include some features discussed in the literature that analyzes the effects of affirmative action policies. Three of them are worth mentioning. First, students could benefit from the presence of individuals from different races, ethnicities, and income's family backgrounds on universities campuses. An environment characterized by diversity, which allows the exchange of different experiences of life among students, could have important impacts on the students' learning experiences, including a reduction in discrimination over time. Second, quotas can make less rare the presence of role models from different races, ethnicities and income's family backgrounds. These individuals who are well successful in their careers, could serve as "examples" to younger individuals from less favorable groups in society, signalling to 
them that they can also succeed in their lives, and serving as an incentive for them to pursue their objectives. Third, the average academic ability of the students in a classroom affects the performance of each of its members. This externality factor is commonly referred and widely accepted in the literature. Quotas, by altering the allocation of human resources among the universities, could certainly affect this externality factor.

However, the empirical evidence in the United States, the country that has adopted more aggressively affirmative action policies, does not indicate that the first two factors (the diversity and the "role model" factors) can impact in a significant way the educational quality of higher education. The last factor, that of externality, would actually reinforce the theoretical results obtained in this paper. ${ }^{32}$

Finally, the system of quotas represents a way of tranferring income to its beneficiaries, black individuals or individuals who have studied in public schools. They can in general attend better universities without incurring the tuition cost. Policymakers who have income transfers to target groups as one of their objectives could use quotas as one instrument to reach their goals. This paper emphasizes the potential trade-off of this policy as the resulting reduction in efficiency. There is an alternative, however, that can accomplish both objectives, of making transfers to target groups and increasing efficiency. It is to eliminate the system of free tuition for all individuals, independently of their family background, who pass the admissions test for the public universities. The system of quotas loses its importance if the government finances, partially or fully, higher education only for those individuals who can not afford it.

\section{References}

Andrade, E. (1998). Growth, distribution, and school policy. University of Chicago Doctoral Dissertation.

Becker, G. (1991). A Treatise on the Family. Harvard University Press, enlarged edition.

Becker, G. (1993). Human Capital: A Theoretical and Empirical Analysis, With Special Reference to Education. The University of Chicago Press.

\footnotetext{
${ }^{32}$ See Holzer and Neumark (2000) for the review of the literature on these and other aspects of the effects of affirmative action policies.
} 
Caucutt, E. \& Kumar, K. (2003). Higher education subsidies and heterogeneity: A dynamic analysis. Journal of Economic Dynamic \& Control, 27:1459-1502.

D’Souza, D. (1991). Illiberal Education. Free Press, New York.

Garrat, R. \& Marshall, J. (1994). Public finance of private goods: The case of college education. Journal of Political Economy, 102(3):566-82.

Heckman, J. (1995). Lessons from the bell curve. Journal of Political Economy, 103(5):1091-1120.

Holzer, H. \& Neumark, D. (2000). Assessing affirmative action. Journal of Economic Literature, 38(3):483-568.

Murray, C. (1994). Affirmative racism. In Debating Affirmative Action: Race, Gender, Ethnicity, and the Politics of Inclusion, pages 191-208. Delta, New York.

Stokey, N. (1996). Free trade, factor returns, and factor accumulation. Journal of Economic Growth, 1(4):421-47.

Stokey, N. (1998). Shirtsleeves to shirtsleeves: The economics of social mobility. In Frontiers of Research in Economic Theory: The Nancy L. Schwartz Memorial Lectures, 1983-1997, pages 210-41. Cambridge University Press. 


\section{Appendix}

Proposition 1: For any given wage differential: there exists an unique $a_{p r, i}^{*}$ which is a function of the wage differential $\left(w_{h, 1}-w_{l, 1}\right)$ such that $a_{p r, i}^{*}\left(w_{h, 1}-w_{l, 1}\right)$ $\in\left(0, a_{p u}\right), i=h, l$, and a parent with $i$ level of human capital sends his child to university if $a \geq a_{p r, i}^{*}\left(w_{h, 1}-w_{l, 1}\right)$, and does not otherwise; and $a_{p r, h}^{*}\left(w_{h, 1}-w_{l, 1}\right)<$ $a_{p r, l}^{*}\left(w_{h, 1}-w_{l, 1}\right)$.

Proof With assumption $3, a_{p r, i}^{*}<a_{p u}, i=h, l$. Using the fact that $\pi_{p r}(0)=0$ from assumption 1 , one obtains:

$$
\begin{aligned}
& u\left((1-\tau) w_{i, 0}-E\right)+\beta\left[\pi_{p r}(0) u\left(w_{h, 1}\right)+\left(1-\pi_{p r}(0)\right) u\left(w_{l, 1}\right)\right] \\
= & u\left((1-\tau) w_{i, 0}-E\right)+\beta u\left(w_{l, 1}\right)<u\left((1-\tau) w_{i, 0}\right)+\beta u\left(w_{l, 1}\right)
\end{aligned}
$$

for any possible value for $w_{l, 1}$. Hence, $a_{p r, i}^{*}>0, i=h, l$. Combining both results, there exist threshold abilities $a_{p r, i}^{*} \in\left(0, a_{p u}\right), i=h, l$, such that a parent with $i$ level of human capital is better off sending his child to private university if his child's ability is greater or equal to $a_{p r, i}^{*}$.

For any given wage differential, parent $i$ sends his child to private university if and only if:

$$
\beta \pi_{p r}(a)\left[u\left(w_{h, 1}\right)-u\left(w_{l, 1}\right)\right]>u\left((1-\tau) w_{i, 0}\right)-u\left((1-\tau) w_{i, 0}-E\right)=A_{i}
$$

With the usual properties of the utility function, $A_{h}<A_{l}$ which implies that $a_{p r, h}^{*}<a_{p r, l}^{*}$ for any wage differential.

Proposition 2: There exists a competitive equilibrium and it is unique.

Proof The equilibrium is characterized by five unknowns $\left(w_{h, 1}, w_{l, 1}, n_{h, 1}, a_{p r, h}\right.$, $a_{p r, l}$ ) and five equations (two first-order conditions of the firm's problem, the law of motion for the variable $n_{h, t}$ and the threshold ability for both types of individuals).

From the first-order conditions for the firm's problem, it is easy to see that $w_{h, 1}$ decreases with $n_{h, 1}$ and $w_{l, 1}$ increases with $n_{h, 1}$. Departing from the situation in which there is only public investment in education and using assumptions 3 and 4, one finds that:

$$
\beta \pi_{p r}\left(a_{p u}\right)\left[u\left(w_{h, 1}^{\prime}\right)-u\left(w_{l, 1}^{\prime}\right)\right]>u\left((1-\tau) w_{i, 0}\right)-u\left((1-\tau) w_{i, 0}-E\right)=A_{i}
$$


where the $v$ individuals with greatest abilities attend the public university and $w_{i, 1}^{\prime}(i=h, l)$ is the wage of individual type $i$ at time 1 if there is no investment in private education. The RHS is constant. As the $L H S$ is greater than the RHS in equation (A.1), individuals from both types of families will invest in private education. They have incentives to reduce the threshold ability (from equation (A.1). Hence, $n_{h, 1}$ (from equation $(2)$ ) and $w_{l, 1}$ (from the firm's first-order condition) increase, and $w_{h, 1}$ (from the firm's first-order condition) decreases . All these changes lead to a reduction in the LHS. As $\pi_{p r}(0)=0$, there is one and only one fraction of individuals with high level of human capital (and then unique wages and threshold abilities) that equates the $L H S$ and the RHS in equation (A.1).

Proposition 3: With $(1-\tau) w_{l, 0}>E$ and $\pi_{p r}(a)=\pi_{p u}(a), \forall a$, the introduction of the system of quotas reduces $E F F_{p u}\left(E F F_{p u}^{* *}<E F F_{p u}^{*}\right)$ and does not affect $a_{p r, l}, a_{p r, h}, E F F_{t o}$ and $\operatorname{DIF}\left(a_{p r, l}^{* *}=a_{p r, l}^{*}, a_{p r, h}^{* *}=a_{p r, h}^{*}, E F F_{t o}^{* *}=E F F_{t o}^{*}\right.$, and $\left.D I F^{* *}=D I F^{*}\right)$.

Proof The following condition must hold in the competitive equilibrium with and without quotas:

$$
\beta \pi_{p r}\left(a_{p r, i}\right)\left[u\left(w_{h, 1}\right)-u\left(w_{l, 1}\right)\right]=u\left((1-\tau) w_{i, 0}\right)-u\left((1-\tau) w_{i, 0}-E\right)=A_{i}
$$

In the competitive equilibrium without quotas, the above equality holds with the combination $a_{p r, i}^{*}$ and $w_{i, 1}^{*}(i=h, l)$. I need to show that, when quotas are introduced, the above equality also holds with the combination $a_{p r, i}^{*}=a_{p r, i}^{* *}$ and $w_{i, 1}^{*}=w_{i, 1}^{* *}$, where $w_{i, 1}^{* *}$ is the wage of individual type $i$ at $t=1$ with quotas.

Suppose that $a_{p r, i}^{*}=a_{p r, i}^{* *}, i=h, l$. Then:

$$
\begin{aligned}
n_{h, 1}^{*} & =n_{h, 0}^{*}\left[\int_{a_{p u}^{*}}^{1} \pi_{p u}(a) f(a) d a+\int_{a_{p r, h}^{*}}^{a_{p u}^{*}} \pi_{p r}(a) f(a) d a\right]+ \\
& +n_{l, 0}^{*}\left[\int_{a_{p u}^{*}}^{1} \pi_{p u}(a) f(a) d a+\int_{a_{p r, l}^{*}}^{a_{p u}^{*}} \pi_{p r}(a) f(a) d a\right]=n_{h, 1}^{\prime} \\
& =n_{h, 0}^{*}\left[\int_{a_{p u, h}^{* *}}^{1} \pi_{p u}(a) f(a) d a+\int_{a_{p r, h}^{* *}}^{a_{p u}^{* *}} \pi_{p r}(a) f(a) d a\right] \\
& +n_{l, 0}^{*}\left[\int_{a_{p u, l}^{* *}}^{1} \pi_{p u}(a) f(a) d a+\int_{a_{p r, l}^{* *}}^{a_{p u}^{* *}} \pi_{p r}(a) f(a) d a\right]
\end{aligned}
$$


where $n_{h, 1}^{\prime}$, the fraction of individuals with high level of human capital at $t=1$ when $a_{p r, i}^{*}=a_{p r, i}^{* *}$ and with quotas, is equal to $n_{h, 1}^{*}$, as $\pi_{p u}(a)=\pi_{p r}(a)$. As $n_{h, 1}^{\prime}=n_{h, 1}^{*}$, then $w_{i, 1}^{*}=w_{i, 1}^{\prime}, i=h, l$, where $w_{i, 1}^{\prime}$ is the wage of individual type $i$ at $t=1$ when $a_{p r, i}^{*}=a_{p r, i}^{* *}$ and with quotas. Hence, the combination $a_{p r, i}^{*}=a_{p r, i}^{* *}$ and $w_{h, i}^{*}=w_{h, i}^{\prime}$ satisfies the following condition that holds in the competitive equilibrium without quotas:

$$
\beta \pi_{p r}\left(a_{p r, i}^{* *}\right)\left[u\left(w_{h, 1}^{\prime}\right)-u\left(w_{l, 1}^{\prime}\right)\right]=u\left((1-\tau) w_{i, 0}\right)-u\left((1-\tau) w_{i, 0}-E\right)=A_{i}
$$

Therefore, $a_{p r, i}^{*}=a_{p r, i}^{* *}$ and $w_{i, 1}^{*}=w_{i, 1}^{\prime}=w_{i, 1}^{* *}$ are part of the competitive equilibrium with quotas, which implies that $D I F^{*}=D I F^{* *}$.

$$
\begin{aligned}
E F F_{t o}^{*} & =\frac{n_{h, 1}^{*}}{\left(v+n_{h, 0}^{*} \int_{a_{p r, h}^{*}}^{a_{p u}^{*}} f(a) d a+n_{l, 0}^{*} \int_{a_{p r, l}^{*}}^{a_{p u}^{*}} f(a) d a\right) E} \\
& =E F F_{t o}^{* *}=\frac{n_{h, 1}^{* *}}{\left(v+n_{h, 0}^{*} \int_{a_{p r, h}^{* *}}^{a_{p u, h}^{* *}} f(a) d a+n_{l, 0}^{*} \int_{a_{p r, l}^{* *}}^{a_{p *}^{* *}} f(a) d a\right) E}
\end{aligned}
$$

as $n_{h, 1}^{*}=n_{h, 1}^{* *}$, and $n_{h, 0}^{*} \int_{a_{p u}^{*}}^{a_{p u, h}^{* *}} f(a) d a=n_{l, 0}^{*} \int_{a_{p u, l}^{* *}}^{a_{p u}^{*}} f(a) d a=q$.

Finally, $E F F_{p u}^{* *}<E F F_{p u}^{*}$, as $n_{h, 0}^{*}\left[\int_{a_{p u, h}^{* *}}^{1} \pi_{p u}(a) f(a) d a\right]+n_{l, 0}^{*}\left[\int_{a_{p u, l}^{* *}}^{1} \pi_{p u}(a)\right.$ $f(a) d a]$ is lower than $n_{h, 0}^{*}\left[\int_{a_{p u}^{*}}^{1} \pi_{p u}(a) f(a) d a\right]+n_{l, 0}^{*}\left[\int_{a_{p u}^{*}}^{1} \pi_{p u}(a) f(a) d a\right]$.

Proposition 4: With $(1-\tau) w_{l, 0}<E$ and $\pi_{p r}(a)=\pi_{p u}(a), \forall a$, the introduction of the system of quotas reduces $E F F_{p u}\left(E F F_{p u}^{* *}<E F F_{p u}^{*}\right)$ and $D I F$ $\left(D I F^{* *}<D I F^{*}\right)$, and increases $a_{p r, h}\left(a_{p r, h}^{* *}>a_{p r, h}^{*}\right)$, and $E F F_{t o}\left(E F F_{t o}^{* *}>\right.$ $\left.E F F_{t o}^{*}\right)$.

Proof The following condition must hold in the competitive equilibrium with and without quotas when $(1-\tau) w_{l, 0}<E$ :

$$
\beta \pi_{p r}\left(a_{p r, h}\right)\left[u\left(w_{h, 1}\right)-u\left(w_{l, 1}\right)\right]=u\left((1-\tau) w_{h, 0}\right)-u\left((1-\tau) w_{h, 0}-E\right)=A_{h}
$$

In the competitive equilibrium without quotas, the above equality holds with the combination $a_{p r, h}^{*}$ and $w_{i, 1}^{*}(i=h, l)$. I need to show that, in the competitive equilibrium with quotas, the above equality holds with $a_{p r, h}^{* *}>a_{p r, h}^{*}$. 
Suppose that $a_{p r, h}^{*}=a_{p r, h}^{* *}$. Then:

$$
\begin{aligned}
n_{h, 1}^{*} & =n_{h, 0}^{*}\left[\int_{a_{p u}^{*}}^{1} \pi_{p u}(a) f(a) d a+\int_{a_{p r, h}^{*}}^{a_{p u}^{*}} \pi_{p r}(a) f(a) d a\right] \\
& +n_{l, 0}^{*} \int_{a_{p u}^{*}}^{1} \pi_{p u}(a) f(a) d a<n_{h, 1}^{\prime} \\
& =n_{h, 0}^{*}\left[\int_{a_{p u, h}^{* *}}^{1} \pi_{p u}(a) f(a) d a+\int_{a_{p r, h}^{* *}}^{a_{p u, h}^{* *}} \pi_{p r}(a) f(a) d a\right] \\
& +n_{l, 0}^{*} \int_{a_{p u, l}^{* *}}^{1} \pi_{p u}(a) f(a) d a,
\end{aligned}
$$

where $n_{h, 1}^{\prime}$, the fraction of individuals with high level of human capital at $t=1$ when $a_{p r, h}^{*}=a_{p r, h}^{* *}$ and with quotas, is greater than $n_{h, 1}^{*}$, as there are now more individuals attending university (that is, $a_{p u, l}^{* *}<a_{p u, l}^{*}$ ). As $n_{h, 1}^{\prime}>n_{h, 1}^{*}$, then $w_{h, 1}^{*}>w_{h, 1}^{\prime}$ and $w_{l, 1}^{*}<w_{l, 1}^{\prime}$, where $w_{i, 1}^{\prime}$ is the wage of individual type $i$ at $t=1$ when $a_{p r, h}^{*}=a_{p r, h}^{* *}$ and with quotas. It means that the skill premium is lower. Hence, the combination $a_{p r, h}^{*}=a_{p r, h}^{* *}$ and $w_{h, i}^{*}=w_{h, i}^{\prime}$ does not satisfy equation (A.3) that must hold in the competitive equilibrium with quotas:

$$
\beta \pi_{p r}\left(a_{p r, h}^{*}\right)\left[u\left(w_{h, 1}^{\prime}\right)-u\left(w_{l, 1}^{\prime}\right)\right]<A_{h}
$$

Hence, $a_{p r, h}^{*}=a_{p r, h}^{* *}$ and $w_{i, 1}^{\prime}$ are not part of the competitive equilibrium with quotas. To restore equality, the $L H S$ must be greater, that is, it is necessary to have a greater $a_{p r, h}$ (less individuals from high income families attending university) which increases the skill premium. Therefore, $a_{p r, h}^{*}<a_{p r, h}^{* *}$ and $n_{h, 1}^{* *}>n_{h, 1}^{*}$ (as $a_{p r, h}^{*}<a_{p r, h}^{* *}$, the skill premium with quotas must be lower than the skill premium without quotas).

As $a_{p r, h}^{*}<a_{p r, h}^{* *}$ and $a_{p u}^{*}>a_{p u, l}^{* *}$, then $D I F^{* *}<D I F^{*}$. For the same reason as in proposition $3, E F F_{p u}^{* *}<E F F_{p u}^{*}$. 
Note that:

$$
E F F_{t o}^{* *}=\frac{n_{h, 1}^{* *}}{\left(v+n_{h, 0}^{*} \int_{a_{p r, h}^{* *}}^{a_{p u}^{* *}} f(a) d a\right) E}=\frac{n_{h, 1}^{* *}}{\left(n_{l, 0}^{*} \int_{a_{p u}^{*}}^{1} f(a) d a+n_{h, 0}^{*} \int_{a_{p r, h}^{* *}}^{1} f(a) d a\right) E}
$$

and,

$$
E F F_{t o}^{*}=\frac{n_{h, 1}^{*}}{\left(v+n_{h, 0}^{*} \int_{a_{p r, h}^{*}}^{a_{p u}^{*}} f(a) d a\right) E}=\frac{n_{h, 1}^{*}}{\left(n_{l, 0}^{*} \int_{a_{p u}^{*}}^{1} f(a) d a+n_{h, 0}^{*} \int_{a_{p r, h}^{*}}^{1} f(a) d a\right) E}
$$
EFF $F_{\text {to }}^{*}$.

As $n_{h, 1}^{* *}>n_{h, 1}^{*}$ and $n_{h, 0}^{*} \int_{a_{p r, h}^{*}}^{1} f(a) d a>n_{h, 0}^{*} \int_{a_{p r, h}^{* *}}^{1} f(a) d a$, then $E F F_{t o}^{* *}>$

Proposition 5: With $\pi_{p u}(a)>\pi_{p r}(a), \forall a$, the introduction of the system of quotas reduces $E F F_{p u}, E F F_{t o}, a_{p r, l}, a_{p r, h}$ and $D I F\left(E F F_{p u}^{* *}<E F F_{p u}^{*}, E F F_{t o}^{* *}<\right.$ $E F F_{t o}^{*}, a_{p r, l}^{* *}<a_{p r, l}^{*}, a_{p r, h}^{* *}<a_{p r, h}^{*}$, and $\left.D I F^{* *}<D I F^{*}\right)$.

Proof The following condition must hold in the competitive equilibrium with and without quotas:

$$
\beta \pi_{p r}\left(a_{p r, i}\right)\left[u\left(w_{h, 1}\right)-u\left(w_{l, 1}\right)\right]=u\left((1-\tau) w_{i, 0}\right)-u\left((1-\tau) w_{i, 0}-E\right)=A_{i}
$$

In the competitive equilibrium without quotas, the above equality holds with the combination $a_{p r, i}^{*}$ and $w_{i, 1}^{*}(i=h, l)$. I need to show that, in the competitive equilibrium with quotas, the above equality holds with $a_{p r, i}^{* *}<a_{p r, i}^{*}$.

Suppose that $a_{p r, h}^{*}=a_{p r, h}^{* *}, i=h, l$. Then:

$$
\begin{aligned}
n_{h, 1}^{*} & =n_{h, 0}^{*}\left[\int_{a_{p u}^{*}}^{1} \pi_{p u}(a) f(a) d a+\int_{a_{p r, h}^{*}}^{a_{p u}^{*}} \pi_{p r}(a) f(a) d a\right] \\
& +n_{l, 0}^{*}\left[\int_{a_{p u}^{*}}^{1} \pi_{p u}(a) f(a) d a+\int_{a_{p r, l}^{*}}^{a_{p u}^{*}} \pi_{p r}(a) f(a) d a\right]>n_{h, 1}^{\prime} \\
& =n_{h, 0}^{*}\left[\int_{a_{p u, h}^{* *}}^{1} \pi_{p u}(a) f(a) d a+\int_{a_{p r, h}^{* *}}^{a_{p u}^{* *}} \pi_{p r}(a) f(a) d a\right]+ \\
& +n_{l, 0}^{*}\left[\int_{a_{p u, l}^{* *}}^{1} \pi_{p u}(a) f(a) d a+\int_{a_{p r, l}^{* *}}^{a_{p u}^{* *}} \pi_{p r}(a) f(a) d a\right]
\end{aligned}
$$


where $n_{h, 1}^{\prime}$, the fraction of individuals with high level of human capital at $t=1$ when $a_{p r, i}^{*}=a_{p r, i}^{* *}$ and with quotas, is lower than $n_{h, 1}^{*}$, as students with greater ability are removed from the best universities, the public ones. As $n_{h, 1}^{\prime}<n_{h, 1}^{*}$, then $w_{h, 1}^{*}<w_{h, 1}^{\prime}$ and $w_{l, 1}^{*}>w_{l, 1}^{\prime}$, where $w_{i, 1}^{\prime}$ is the wage of individual type $i$ at $t=1$ when $a_{p r, i}^{*}=a_{p r, i}^{* *}$ and with quotas. It means that the skill premium is greater. Hence, the combination $a_{p r, i}^{*}=a_{p r, i}^{* *}$ and $w_{h, i}^{*}=w_{h, i}^{\prime}$ does not satisfy equation (A.4) that must hold in the competitive equilibrium with quotas:

$$
\beta \pi_{p r}\left(a_{p r, i}^{*}\right)\left[u\left(w_{h, 1}^{\prime}\right)-u\left(w_{l, 1}^{\prime}\right)\right]>A_{i}
$$

Hence, $a_{p r, i}^{*}=a_{p r, i}^{* *}$ and $w_{i, 1}^{\prime}$ are not part of the competitive equilibrium with quotas. To restore equality, the $L H S$ must be lower, that is, it is necessary to have a lower $a_{p r, i}$ (more individuals from high and low income families attending university) which reduces the skill premium. Therefore, $a_{p r, i}^{*}>a_{p r, i}^{* *}$ and $n_{h, 1}^{* *}<$ $n_{h, 1}^{*}$ (as $a_{p r, i}^{*}>a_{p r, i}^{* *}$, the skill premium with quotas must be greater than the skill premium without quotas).

Due to the concavity of the probability function (assumption 1), the reduction in $a_{p r, l}$ is greater than the one in $a_{p r, h}$ to reach the equilibrium in equation (A.4). Therefore, $D I F^{* *}<D I F^{*}$.

For the same reason as in proposition $3, E F F_{p u}^{* *}<E F F_{p u}^{*}$.

Note that:

$$
E F F_{t o}^{* *}=\frac{n_{h, 1}^{* *}}{\left(v+n_{h, 0}^{*} \int_{a_{p r, h}^{* *}}^{a_{u, h}^{* *}} f(a) d a+n_{l, 0}^{*} \int_{a_{p r, l}^{* *}}^{a_{p u}^{* *}} f(a) d a\right) E}
$$

and,

$$
E F F_{t o}^{*}=\frac{n_{h, 1}^{*}}{\left(v+n_{h, 0}^{*} \int_{a_{p r, h}^{*}}^{a_{p u}^{*}} f(a) d a+n_{l, 0}^{*} \int_{a_{p r, l}^{*}}^{a_{p u}^{*}} f(a) d a\right) E}
$$

As $n_{h, 1}^{* *}<n_{h, 1}^{*}$ and , $n_{h, 0}^{*} \int_{a_{p r, h}^{* *}}^{a_{p * h}^{* *}} f(a) d a+n_{l, 0}^{*} \int_{a_{p r, l}^{* *}}^{a_{p * l}^{* *}} f(a) d a>n_{h, 0}^{*} \int_{a_{p r, h}^{*}}^{a_{p u}^{*}} f(a) d a+$ $n_{l, 0}^{*} \int_{a_{p r, l}^{*}}^{a_{p u}^{*}} f(a) d a$, then $E F F_{t o}^{* *}<E F F_{t o}^{*}$.

Proposition 6: With $\pi_{p u}(a)<\pi_{p r}(a), \forall a$, the introduction of the system of quotas reduces $E F F_{p u}\left(E F F_{p u}^{* *}<E F F_{p u}^{*}\right)$, and it increases $E F F_{t o}, a_{p r, l}, a_{p r, h}$ and $D I F\left(E F F_{t o}^{* *}>E F F_{t o}^{*}, a_{p r, l}^{* *}>a_{p r, l}^{*}, a_{p r, h}^{* *}>a_{p r, h}^{*}\right.$, and $\left.D I F^{* *}>D I F^{*}\right)$. 
Proof The following condition must hold in the competitive equilibrium with and without quotas:

$$
\beta \pi_{p r}\left(a_{p r, i}\right)\left[u\left(w_{h, 1}\right)-u\left(w_{l, 1}\right)\right]=u\left((1-\tau) w_{i, 0}\right)-u\left((1-\tau) w_{i, 0}-E\right)=A_{i}
$$

In the competitive equilibrium without quotas, the above equality holds with the combination $a_{p r, i}^{*}$ and $w_{i, 1}^{*}(i=h, l)$. I need to show that, in the competitive equilibrium with quotas, the above equality holds with $a_{p r, i}^{* *}>a_{p r, i}^{*}$.

Suppose that $a_{p r, h}^{*}=a_{p r, h}^{* *}, i=h, l$. Then:

$$
\begin{aligned}
n_{h, 1}^{*} & =n_{h, 0}^{*}\left[\int_{a_{p u}^{*}}^{1} \pi_{p u}(a) f(a) d a+\int_{a_{p r, h}^{*}}^{a_{p u}^{*}} \pi_{p r}(a) f(a) d a\right] \\
& +n_{l, 0}^{*}\left[\int_{a_{p u}^{*}}^{1} \pi_{p u}(a) f(a) d a+\int_{a_{p r, l}^{*}}^{a_{p u}^{*}} \pi_{p r}(a) f(a) d a\right]<n_{h, 1}^{\prime} \\
& =n_{h, 0}^{*}\left[\int_{a_{p u}^{* *}}^{1} \pi_{p u}(a) f(a) d a+\int_{a_{p r, h}^{* *}}^{a_{p u, h}^{* *}} \pi_{p r}(a) f(a) d a\right] \\
& +n_{l, 0}^{*}\left[\int_{a_{p u, l}^{* *}}^{1} \pi_{p u}(a) f(a) d a+\int_{a_{p r, l}^{* *}}^{a_{p u}^{* *}} \pi_{p r}(a) f(a) d a\right]
\end{aligned}
$$

where $n_{h, 1}^{\prime}$, the fraction of individuals with high level of human capital at $t=1$ when $a_{p r, i}^{*}=a_{p r, i}^{* *}$ and with quotas, is greater than $n_{h, 1}^{*}$, as students with greater ability are transferred to the best universities, the private ones. As $n_{h, 1}^{\prime}>n_{h, 1}^{*}$, then $w_{h, 1}^{*}>w_{h, 1}^{\prime}$ and $w_{l, 1}^{*}<w_{l, 1}^{\prime}$, where $w_{i, 1}^{\prime}$ is the wage of individual type $i$ at $t=1$ when $a_{p r, i}^{*}=a_{p r, i}^{* *}$ and with quotas. It means that the skill premium is lower. Hence, the combination $a_{p r, i}^{*}=a_{p r, i}^{* *}$ and $w_{h, i}^{*}=w_{h, i}^{\prime}$ does not satisfy equation (A.4) that must hold in the competitive equilibrium with quotas:

$$
\beta \pi_{p r}\left(a_{p r, i}^{*}\right)\left[u\left(w_{h, 1}^{\prime}\right)-u\left(w_{l, 1}^{\prime}\right)\right]<A_{i}
$$

Hence, $a_{p r, i}^{*}=a_{p r, i}^{* *}$ and $w_{i, 1}^{\prime}$ are not part of the competitive equilibrium with quotas. To restore equality, the LHS must be greater, that is, it is necessary to have a higher $a_{p r, i}$ (less individuals from high and low income families attending university) which increases the skill premium. Therefore, $a_{p r, i}^{*}<a_{p r, i}^{* *}$ and $n_{h, 1}^{* *}>$ $n_{h, 1}^{*}\left(\right.$ as $a_{p r, i}^{*}<a_{p r, i}^{* *}$, the skill premium with quotas must be lower than the skill premium without quotas). 
Due to the concavity of the probability function (assumption 1), the increase in $a_{p r, l}$ is greater than the one in $a_{p r, h}$ to reach the equilibrium in equation (A.4). Therefore, $D I F^{* *}>D I F^{*}$.

For the same reason as in proposition $3, E F F_{p u}^{* *}<E F F_{p u}^{*}$.

Note that:

$$
E F F_{t o}^{* *}=\frac{n_{h, 1}^{* *}}{\left(v+n_{h, 0}^{*} \int_{a_{p r, h}^{* *, h}}^{a_{p u}^{* *}} f(a) d a+n_{l, 0}^{*} \int_{a_{p r, l}^{* *, l}}^{a_{p u}^{* *}} f(a) d a\right) E}
$$

and,

$$
E F F_{t o}^{*}=\frac{n_{h, 1}^{*}}{\left(v+n_{h, 0}^{*} \int_{a_{p r, h}^{*}}^{a_{p u}^{*}} f(a) d a+n_{l, 0}^{*} \int_{a_{p r, l}^{*}}^{a_{p u}^{*}} f(a) d a\right) E}
$$

As $n_{h, 1}^{* *}>n_{h, 1}^{*}$ and,$n_{h, 0}^{*} \int_{a_{p r, h}^{* *, h}}^{a_{p *}^{* *}} f(a) d a+n_{l, 0}^{*} \int_{a_{p r, l}^{*}}^{a_{p, l}^{* *}} f(a) d a<n_{h, 0}^{*} \int_{a_{p r, h}^{*}}^{a_{p u}^{*}} f(a) d a+$ $n_{l, 0}^{*} \int_{a_{p r, l}^{*}}^{a_{p u}^{*}} f(a) d a$, then $E F F_{t o}^{* *}>E F F_{t o}^{*}$. 